\title{
Trilha Interpretativa para crianças do Ensino Fundamental: uso de situações lúdicas, sensoriais e culturais em Caçu, Goiás, Brasil
}

Interpretive Trail for Elementary School children: use of playful, sensory and cultural situations in Caçu, Goiás, Brazil

Sendero interpretativo para niños de Escuela Primaria: uso de situaciones lúdicas, sensoriales y culturales en Caçu, Goiás, Brasil

Isa Lucia de Morais

ORCID: https://orcid.org/0000-0001-8748-9723 Universidade Estadual de Goiás, Brasil

E-mail: isamorais1@gmail.com

Renata Martins Campos

ORCID: https://orcid.org/0000-0002-5177-3009 Universidade Estadual de Goiás, Brasil E-mail: rmcamposbio@ hotmail.com Núbia Aparecida Alves Costa

ORCID: https://orcid.org/0000-0001-8981-1309 Universidade Estadual de Goiás, Brasil E-mail: nubiaaacosta598@gmail.com

Vitória Aparecida de Oliveira Ferreira ORCID: https://orcid.org/0000-0002-7331-6861 Universidade Estadual de Goiás, Brasil E-mail: vitoria.aof1@gmail.com

\begin{abstract}
Resumo
A Educação Ambiental é um instrumento eficiente no processo educacional, tendo em vista o envolvimento da comunidade escolar e a sensibilização na formação ambiental das pessoas. Neste viés, o objetivo desta pesquisa foi implantar uma trilha interpretativa com o uso de situações lúdicas, sensoriais e culturais para crianças do Ensino Fundamental no Lago Municipal de Caçu, Goiás. O percurso da Trilha Interpretativa foi realizado com um públicoalvo constituído por 17 crianças de 7 a 8 anos, de uma das turmas do $2^{\circ}$ Ano do Ensino Fundamental, turno vespertino da Escola Municipal Olívio Girotto, com o acompanhamento da professora e uma monitora da turma. Foi planejada, ao longo da Trilha Interpretativa, uma sequência de atividades lúdico-pedagógicas, educativas e recreativas, abrangendo temas relacionados ao meio ambiente e sua conservação. O percurso da Trilha Interpretativa pelo públicoalvo teve duração de uma hora e as crianças mostraram-se interessadas e curiosas pelo ambiente que as cercava o tempo todo. Após a visita, foram observadas mudanças no comportamento do público-alvo, comprovadas por relatos e desenhos de observações da natureza e mudanças de postura frente a situações de conservação ambiental. Isso mostra a importância de despertar nas crianças a curiosidade sobre a natureza e aguçar o seu olhar tanto para os fenômenos ecológicos quanto para os impactos ambientais resultantes das ações antrópicas, utilizando como ferramenta socioeducativa a Trilha Interpretativa.
\end{abstract}

Palavras-chave: Áreas verdes urbanas; Desenhos; Educação ambiental; Percepção ambiental; Trilhas ecológicas.

\begin{abstract}
Environmental Education is an efficient instrument in the educational process, with a view to involving the school community and raising awareness in people's environmental education. In this perspective, the objective of this research was to implement an interpretive trail with the use of playful, sensory and cultural situations for elementary school children in the Municipal Lake of Caçu, Goiás. The Interpretative Trail route was carried out with a target audience consisting of 17 children from 7 to 8 years old, from one of the classes of the 2nd year of Elementary School, in the afternoon shift at Escola Municipal Olívio Girotto, with the monitoring of the teacher and a monitor of the class. Along the Interpretative Trail, a sequence of playful-pedagogical, educational and recreational activities was planned, covering themes related to the environment and its conservation. The path of the Interpretative Trail by the target audience lasted an hour and the children were interested and curious about the environment that surrounded them all the time. After the visit, changes in the behavior of the target audience were observed, as evidenced by reports and drawings of observations of nature and changes in attitude towards situations of environmental conservation. This shows the importance of awakening children's curiosity about nature and sharpening their eyes
\end{abstract}


both to ecological phenomena and to the environmental impacts resulting from anthropic actions, using the Interpretative Trail as a socio-educational tool.

Keywords: Green areas; Drawings; Environmental education; Environmental perception; Ecological trails.

\section{Resumen}

La Educación Ambiental es un instrumento eficaz en el proceso educativo, con miras a involucrar a la comunidad escolar y sensibilizar en la educación ambiental de las personas. En esta perspectiva, el objetivo de esta investigación fue implementar un sendero interpretativo utilizando situaciones lúdicas, sensoriales y culturales para niños de primaria en el Lago Municipal de Caçu, Goiás. La ruta Sendero Interpretativo se realizó con un público objetivo compuesto por 17 niños. de 7 a 8 años, de una de las clases en el $2^{\circ}$ año de primaria, en el turno de tarde en la Escola Municipal Olívio Girotto, con el seguimiento del profesor y un monitor de la clase. A lo largo del Sendero Interpretativo se planificó una secuencia de actividades lúdico-pedagógicas, educativas y recreativas, que abarcaron temas relacionados con el medio ambiente y su conservación. El recorrido del Sendero Interpretativo por parte del público objetivo duró una hora y los niños se mostraron interessados y curiosos por el entorno que los rodeaba todo el tiempo. Luego de la visita, se observaron cambios en el comportamiento del público objetivo, como lo evidencian los reportes y dibujos de observaciones de la naturaleza y cambios de actitud ante situaciones de conservación ambiental. Esto muestra la importancia de despertar la curiosidad de los niños sobre la naturaleza y agudizar la mirada tanto a los fenómenos ecológicos como a los impactos ambientales derivados de las acciones antrópicas, utilizando el Sendero Interpretativo como herramienta socioeducativa.

Palabras clave: Zonas verdes urbanas; Dibujos; Educación ambiental; Percepción ambiental; Senderos ecológicos.

\section{Introdução}

As intensas alterações no meio ambiente, a exploração predatória dos recursos naturais, somadas à veiculação na mídia das constantes catástrofes ambientais têm despertado na sociedade um olhar diferente no tocante às questões ambientais. A dimensão social dessa situação requer ações de enfrentamento para o tempo presente e futuro e o esforço em prol de contribuir para a aquisição do repertório da cultura da sustentabilidade em suas múltiplas dimensões, entre elas as práticas sociais e institucionais, as doutrinas político-ideológicas, as condições socioeconômicas e culturais, e também, a compreensão da magnitude dos problemas ambientais e do saber ambiental necessário à compreensão da vida e da relação humanosociedade-natureza (Morais et al., 2021a; Morais et al., 2021b; Nunes et al., 2021; Rocha et al., 2021).

Neste viés, a Educação Ambiental (EA) é um instrumento eficiente nesse processo, tendo em vista o envolvimento da comunidade escolar e a influência nos ideais de futuros formadores de opinião. De acordo com a Política Nacional de Educação Ambiental (Lei n ${ }^{\circ}$ 9795/1999, Art. $1^{\circ}$ ) a EA abrange um conjunto de processos por meio dos quais o indivíduo e a coletividade constroem valores sociais, conhecimentos, habilidades, atitudes e competências voltadas para a conservação do meio ambiente, bem de uso comum do povo, essencial à sadia qualidade de vida e sua sustentabilidade (Brasil, 1999; Morais et al., 2021a; Morais et al. 2021b).

A EA possui muitas dimensões e aborda diferentes temas, e entre eles está a importância das áreas verdes urbanas para a sociedade, nas quais podem ser desenvolvidas atividades educativas e recreacionais que subsidiem a tomada de consciência, responsabilidade e respeito frente ao meio ambiente e oportunizem uma mudança de atitude em relação à conservação da vegetação urbana, e, concomitantemente, contribuem para a melhoria da qualidade de vida da comunidade local (Morais et al., 2021b; Neres et al., 2021; Peixoto et al., 2021; Rocha et al., 2021; Silvestrim et al., 2021). De acordo com o Art. $8^{\circ}, \S 1^{\circ}$, da Resolução CONAMA No 369/2006, considera-se área verde "o espaço de domínio público que desempenhe função ecológica, paisagística e recreativa, propiciando a melhoria da qualidade estética, funcional e ambiental da cidade, sendo dotado de vegetação e espaços livres de impermeabilização" (CONAMA, 2006).

As áreas verdes urbanas são consideradas o conjunto de áreas intraurbanas que apresentam cobertura vegetal, arbórea (nativa e ou introduzida), arbustiva ou rasteira (gramíneas) e que promove de modo significativo a qualidade de vida e o equilíbrio ambiental nas cidades. Essas áreas verdes estão presentes numa variedade de situações: em espaços públicos; em áreas de preservação permanente (APP); nos canteiros centrais; nas praças, parques, florestas e unidades de conservação (UC) 
urbanas; nos jardins institucionais; e nos terrenos públicos não edificados (MMA, 2017; Morais et al., 2021b; Neres et al., 2021; Rocha et al., 2021).

Nas cidades, as áreas verdes expõem as pessoas à natureza e, desse modo, facilita sua apreciação. Esses locais também proporcionam oportunidades para recreação, saúde e relaxamento, além de coesão comunitária. O acesso a áreas verdes foi relacionado a uma redução na mortalidade e melhora na saúde em geral. Os benefícios psicológicos dos espaços verdes aumentam com a biodiversidade e uma "vista verde" de uma janela aumenta a satisfação e reduz o estresse nas áreas urbanas. Isso pode ter um efeito bastante positivo sobre a produtividade econômica e, assim, na prosperidade regional. Diversos estudos mostram que o valor da propriedade (medido por preços hedônicos) aumenta com a proximidade a áreas verdes (Secretariat of the Convention on Biological Diversity, 2012; Morais et al., 2021b; Neres et al., 2021).

Entre as funções das áreas verdes estão: i) a ecológica: pela presença da vegetação, a qual oferece diversos recursos à fauna urbana; do solo não impermeabilizado e de uma fauna mais diversificada nas suas proximidades, promovendo melhorias no clima dos bairros, nas suas proximidades e na qualidade do ar, água e solo; ii) a estética diz respeito à diversificação da paisagem construída e o embelezamento da cidade; e iii) a do ponto de vista cultural, desenvolvida por estabelecer uma pedagogia de educação ambiental e permitir que as presentes e futuras gerações possam desfrutar das áreas verdes e conserválas (Vidigal \& Resende, 2011; Ibiapino \& Nääs, 2020; Barros et al., 2021; Neres et al., 2021). Além disso, as áreas verdes são espaços geradores de conhecimento científico e uma gama de ferramentas de cunho educativo, os quais devem ser socializados para promover reflexões sobre o meio ambiente buscando conscientizar a população sobre a importância da conservação da biodiversidade (Verde et al., 2020; Morais et al., 2021b). Assim, a valorização das áreas verdes urbanas através da Educação Ambiental, constitui-se como uma estratégia-ação primordial para a tomada de consciência que permite o desenvolvimento de atitudes comportamentais favoráveis à conservação e preservação da biodiversidade.

Como ferramenta de cunho socioeducativo e de Educação Ambiental, um dos trabalhos que pode ser desenvolvido nas áreas verdes são as trilhas interpretativas, onde situações lúdicas, sensoriais e culturais podem ser promovidas com alunos de diferentes faixas etárias, em especial os da Educação Infantil e das etapas iniciais do Ensino Fundamental. Propor atividades em áreas verdes, envolvendo educadores e alunos, tem o intuito de desenvolver a conscientização ambiental, estimular aspectos sensoriais como cheiros, sabores, texturas, muito importantes no desenvolvimento intelectual dessa faixa etária, além de possibilitar a formação da Alfabetização Ambiental (Capra, 2002; Alvarenga et al., 2018). A Alfabetização Ambiental abrange a compreensão dos princípios básicos de organização das comunidades ecológicas e a capacidade de incluí-los na vida diária das comunidades humanas, sendo este tipo de ensino considerado o mais importante da educação na atualidade (Capra, 2002; Dick et al., 2020).

Um dos aspectos relevantes da Alfabetização Ambiental é o contato e reconhecimento da flora e fauna locais, proporcionando conhecimentos sobre meio ambiente, seres vivos, relações ecológicas e utilização de recursos naturais para atividades econômicas, científicas e culturais. Acredita-se que ambientes variados podem favorecer diferentes tipos de interações e que o professor tem papel importante como organizador dos espaços onde ocorre o processo educacional (Ministério da Educação, 2006; Morais et al., 2021a). Neste contexto, o reconhecimento da importância das áreas verdes urbanas e as possibilidades de sua utilização em atividades de extensão, ensino e pesquisa motivaram a realização deste estudo, no qual objetivamos analisar a percepção de crianças do Ensino Fundamental quanto ao uso de uma trilha interpretativa mediante situações lúdicas, sensoriais e culturais no Lago Municipal de Caçu, Goiás.

\section{Material e Métodos}

A pesquisa foi realizada em uma área de reflorestamento de aproximadamente $8.524 \mathrm{~m}^{2}$, no Lago Municipal de Caçu, localizado no Setor Água Fria da área urbana de Caçu, Goiás. No local ainda existem vestígios de uma mata de galeria, com a 
presença de buritis (Mauritia flexuosa L. f.) (Figura 1). A área do Lago Municipal de Caçu é muito usada para caminhadas, corridas e para recreação das crianças. Vale ressaltar que esta área de reflorestamento até então, não tinha nenhuma atividade de cunho educacional implementada.

Figura 1. Lago Municipal de Caçu, Caçu, Goiás. A seta indica a mata de galeria onde foi implementada a Trilha Interpretativa.

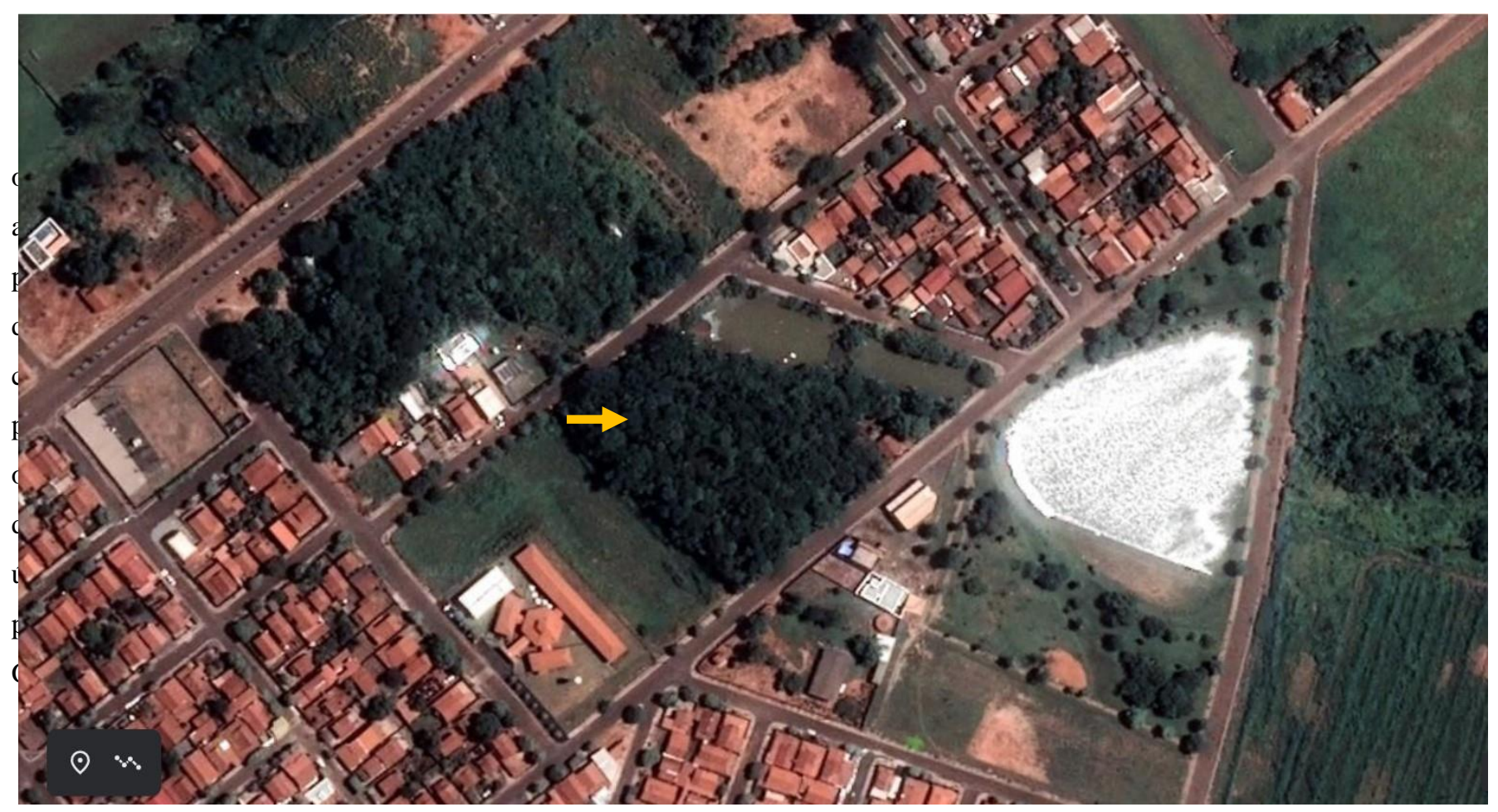

Fonte: Google Earth (2021).

No setor Água Fria reside boa parte dos alunos da Escola Municipal Olívio Girotto. Por este motivo, o público-alvo escolhido para participarem da trilha interpretativa foram 17 crianças desta escola, de 7 a 8 anos, da turma do $2^{\circ}$ Ano do Ensino Fundamental, turno vespertino. Juntamente com as crianças, participaram da trilha uma professora e uma monitora da turma. A escolha do público-alvo, além da localização da escola, foi por causa da necessidade da formação da consciência ambiental desde a infância, acreditando serem essas crianças, propagadoras no futuro de ações de preservação ambiental. Além disso, há o desenvolvimento do cuidado da saúde do ambiente que os cercam, visto que, muitos passam pelo entorno do Lago Municipal de Caçu todos os dias.

Para dar início à pesquisa foi necessário obter o consentimento dos gestores da escola envolvida. Para tal, estes foram informados sobre os objetivos e importância desta pesquisa em EA. Depois do consentimento dos gestores da escola foi feito o contato com os pais dos alunos participantes da pesquisa. Neste contato, apresentamos os objetivos da pesquisa e a garantia do sigilo como premissa ética entre pesquisador e entrevistados. O consentimento dos participantes foi formalizado através de Termo de Consentimento, conforme exigências da Resolução n ${ }^{\circ}$ 466, de 12 de dezembro de 2012, do Conselho Nacional de Saúde do Ministério da Saúde, a qual estabelece que se tratando da realização de pesquisa com seres humanos, o indivíduo a ser pesquisado deve conhecer os objetivos e o modo como os dados serão utilizados (CNS, 2012). Como o público-alvo da pesquisa é menor de idade, foram necessários o consentimento e a assinatura dos pais no referido termo. Houve o consentimento de todos os pais para que seus filhos participassem da pesquisa.

O inciso V do parágrafo único da Resolução n 510 , de 07 de abril de 2016, estabelece que não serão registradas nem avaliadas pelo sistema CEP/CONEP (Comitês de Ética em Pesquisa/Comissão Nacional de Ética em Pesquisa) pesquisa com 
bancos de dados, cujas informações são agregadas, sem possibilidade de identificação individual (CNS, 2016). Por entendermos que os dados da presente pesquisa se enquadram neste item não houve a submissão deste estudo no Comitê de Ética em Pesquisa com seres humanos.

Antes da visita do público-alvo fomos no Lago Municipal de Caçu para elaborar o percurso e as atividades da Trilha Interpretativa. Foram planejadas paradas em oito pontos estratégicos, usando como critério os aspectos sensoriais que esses espaços pudessem despertar nas crianças.

\section{Resultados e Discussão}

Uma das primeiras etapas de execução da pesquisa foi a criação do percurso da Trilha Interpretativa. Ao se planejar a construção de uma Trilha Interpretativa é importante criar roteiros interpretativos coerentes e eficientes, baseados nos diferentes aspectos existentes ao longo da trilha e nas principais informações e conceitos que se deseja transmitir (Santos et al., 2011; Alvarenga et al., 2018; Rocha \& Henrique, 2020). Há que se pensar também nos recursos presentes ao longo do percurso da trilha, os quais serão utilizados para a execução de atividades lúdico pedagógicas, objetivando o desenvolvimento das múltiplas inteligências (musical, lógico matemático, espacial, interpessoal, intrapessoal, linguística e cinestésica) (Gardner, 1995; Santos et al., 2011).

Para tanto, foram definidos os temas a serem interpretados que estimulam a observação, a reflexão e a ação ao longo da Trilha Interpretativa, com uma sequência de atividades lúdico-pedagógicas, educativas e recreativas, abrangendo temas relacionados ao meio ambiente e sua conservação. Além disso, os aspectos considerados para elaboração da trilha foram: a) acesso - fácil, sem declives, sem obstáculos, buracos, que poderiam ocasionar acidentes com as crianças e que fosse acessível a diversos tipos de participantes; b) sombreamento - que permitisse maior conforto térmico ao público-alvo; c) aspectos sensoriais - indivíduos arbóreos floridos ou com frutos, caules espinhosos ou suberosos, frutos dispersando suas sementes, além de ninhos, cupinzeiros, tocas de corujas, formigueiros, ou seja, situações que oportunizassem ao público-alvo as diversas sensações que remetem o ambiente natural; e d) presença de lixo no local - as crianças foram orientadas a atuarem como "Fiscais da Natureza" com a proposta de recolherem o lixo encontrado ao longo da Trilha Interpretativa e colocá-lo em sacos plásticos e, posteriormente, dar uma destinação correta ao mesmo.

Além destes aspectos, foram priorizadas situações que causassem sensibilização das crianças, como a proximidade das vias públicas, onde observa-se uma maior degradação ambiental devido ao descarte inadequado de lixo, gerando entre outros, a contaminação da água do lago. Logo, a Trilha Interpretativa foi implementada na área reflorestada, a qual apresenta espécies nativas do Cerrado, arbóreas ornamentais e frutíferas exóticas. A importância de dar continuidade à recuperação e conservação da vegetação ripária foi outro critério relevante para escolha do percurso da trilha, devido às áreas de nascentes, as quais tem a função ecológica de proteção do recurso hídrico.

Alguns indivíduos arbóreos foram marcados com fita zebrada ao longo dos $250 \mathrm{~m}$ da Trilha Interpretativa, delimitando o caminho a ser percorrido e para que este pudesse ser utilizado por outros estudantes. Posteriormente, essas fitas serão substituídas por plaquetas ou similares, evitando, assim, a geração de resíduo no ambiente.

Quando a Trilha Interpretativa é percorrida com o auxílio de guias ou monitores, sugere-se a existência de pontos de parada situados em locais estratégicos, que apresentem aspectos relevantes a serem abordados (Andrade \& Rocha, 2008). Um indivíduo de ipê-roxo (Handroanthus impetiginosus (Mart. ex DC.) Mattos) foi uma das paradas escolhidas (Parada 4, Figura 2), pois sua beleza cênica chama a atenção das pessoas e desperta nestas um sentimento acerca da importância da conservação ambiental. Além disso, recomenda-se que o número de paradas não seja excessivo, principalmente quando a atividade envolver crianças, que majoritariamente se dispersam com facilidade. Portanto, a demora em demasia pode prejudicar o trabalho de interpretação. Assim, a Trilha Interpretativa foi construída subsidiada por um percurso com a realização de pontos de parada: 
Parada 1 - observação do caule; Parada 2 - dispersão e coleta de sementes; Parada 3 - tocando as folhas; Parada 4 - floração do ipê; Parada 5 - observação da fauna; Parada 6 - metamorfose do inseto; Parada 7 - canto dos pássaros; e Parada 8 - coleta do lixo (Figura 2).

Figura 2. Mapa ilustrativo dos pontos de parada estabelecidos na Trilha Interpretativa no Lago Municipal de Caçu, Caçu, Goiás.

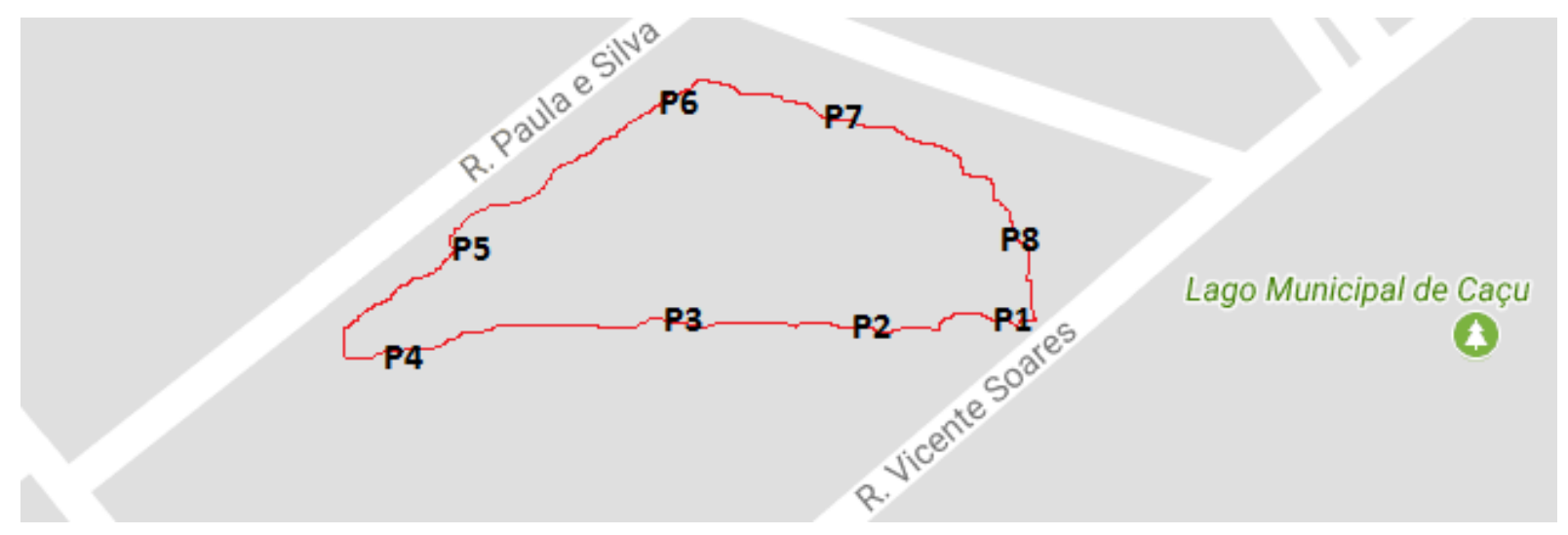

Fonte: Autores.

Antes de irem para a Trilha Interpretativa as crianças lancharam e foram orientadas a levarem garrafas com água potável, irem com calçados fechados e usarem repelentes. A visita à Trilha Interpretativa do Lago Municipal de Caçu iniciouse com um momento de acolhida, na qual foi feita uma roda e as crianças foram convidadas a observar e sentir o que ocorria à sua volta usando os seus sentidos visão, olfato, audição, paladar e tato. Dessa forma eles podiam sentir a temperatura do ambiente, o cheiro, visualizar as cores e sentir o sabor e a textura do mundo do qual fazem parte. Neste momento foi enfatizado para os alunos sobre: o motivo de realizarem o percurso da trilha; a importância de se estudar a biodiversidade para auxiliar na sua conservação; o cuidado que se deve ter quanto a dar um destino correto ao lixo; os cuidados que deveriam ser adotados ao caminhar na trilha, entre eles onde pisar, tocar, o silêncio para ouvir, entre outros.

Após a acolhida, as crianças iniciaram o percurso da Trilha Interativa. Nestes pontos, as atividades de cunho sensorial foram trabalhadas como: tocar os troncos (Figura 3), folhas, flores, frutos, observando texturas, cores, perfumes e até mesmo sabores. Os nomes vulgares de algumas plantas foram citados, bem como suas utilizações no cotidiano. Ao longo de todo o percurso perguntas simples foram feitas como: “Alguém conhece...”, “Já comeu...”, "Sabia que isso é usado para...”. Isso contribuiu para assegurar a interação entre o grupo o tempo todo. Como a trilha não pode ser "engessada" houve momentos com situações inusitadas como a "teia da aranha", que foi uma surpresa não programada, mas digna de parada devido à curiosidade despertada nas crianças.

Diante desta vivência, percebe-se que o percurso de uma Trilha Interpretativa orienta-se não para conteúdos ou o conhecimento formal, mas antes de tudo, para atuar sobre dois eixos fundamentais: interação e a brincadeira. Entre os critérios estabelecidos pelo Ministério da Educação para assegurar os direitos integrais das crianças estão o direito à brincadeira, à atenção individual, a um ambiente aconchegante, seguro e estimulante e ao contato com a natureza (Campos \& Rosemberg, 2009; Matos et al., 2021). A proposta pedagógica e as atividades desenvolvidas na Trilha Interpretativa devem considerar estes critérios e refletir esta preocupação. Dessa forma, a Trilha Interpretativa, enquanto espaço não formal de EA, se torna palpável, dinâmica, viva, “brincável”, explorável, transformável, acessível e real para as crianças (Figura 4). 
Figura 3. Interação entre as crianças e elementos naturais ao longo da Trilha Interpretativa no Lago Municipal de Caçu, Caçu, GO.

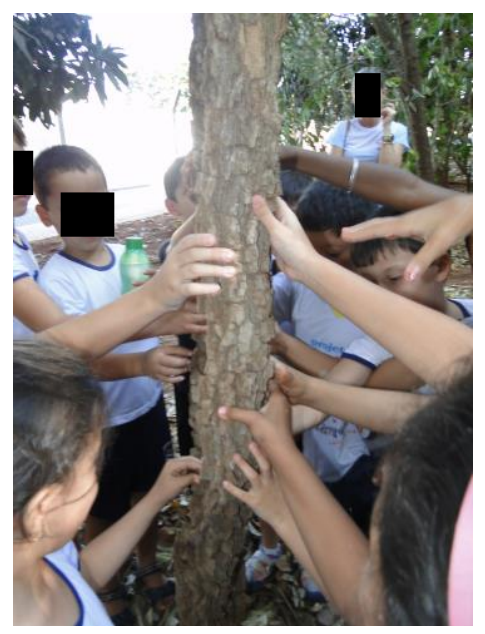

Fonte: Autores.

Figura 4. As crianças aprendendo a cuidar dos indivíduos jovens de plantas (A) e o momento de realização de brincadeiras em contato com a natureza (B) ao longo do percurso da Trilha Interpretativa no Lago Municipal de Caçu, Caçu, GO.

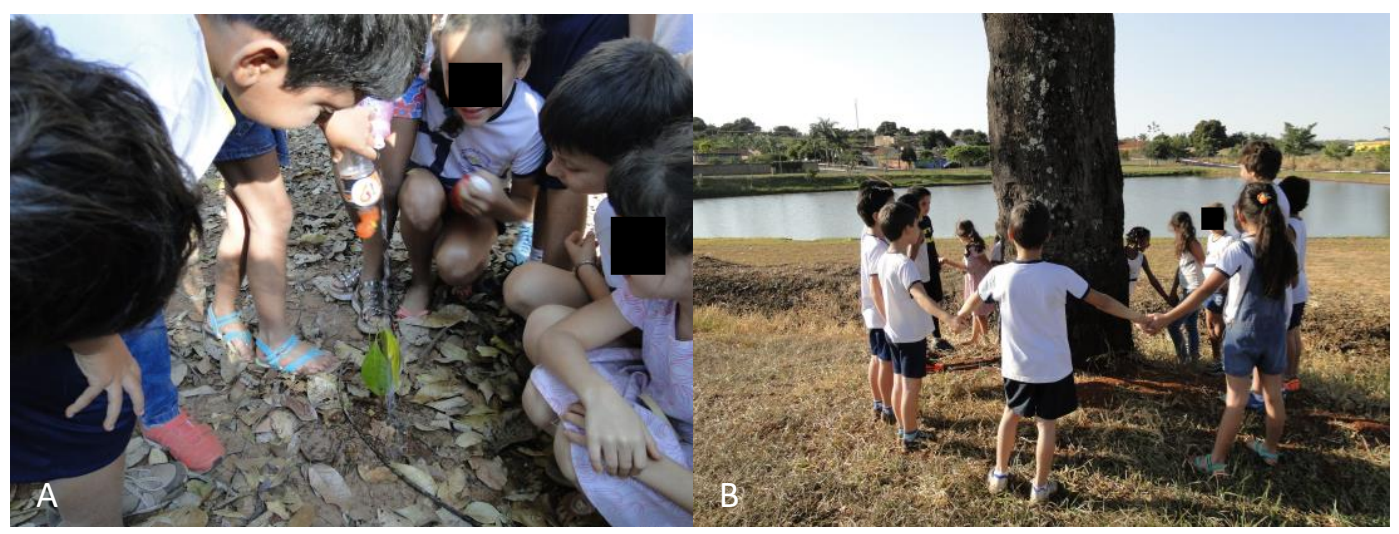

Fonte: Autores.

De forma acessível à faixa etária das crianças foram feitos esclarecimentos sobre os seres vivos, ciclo de vida, importância da conservação ambiental ao longo da Trilha Interpretativa. As crianças puderam observar diversos animais, entre eles, aves (Figura 5, A), insetos, lagartos, bem como vestígios da presença deles no ambiente como fezes e penas, além das fenofases das plantas, em especial a dispersão das sementes (Figura 5, B-C). A observação destes seres vivos e suas interações com o ambiente físico comprova que o espaço natural é uma ferramenta facilitadora e instigadora do conhecimento e da sensibilização de seus visitantes, além de poder contribuir para que o educando repense seu estilo de vida e sua visão do mundo a partir da percepção da realidade ambiental (Alvarenga et al., 2018). 
Figura 5. Aves que foram visualizadas (A) e coleta de sementes (B-C) pelas crianças ao longo do percurso da Trilha Interpretativa no Lago Municipal de Caçu, Caçu, GO.

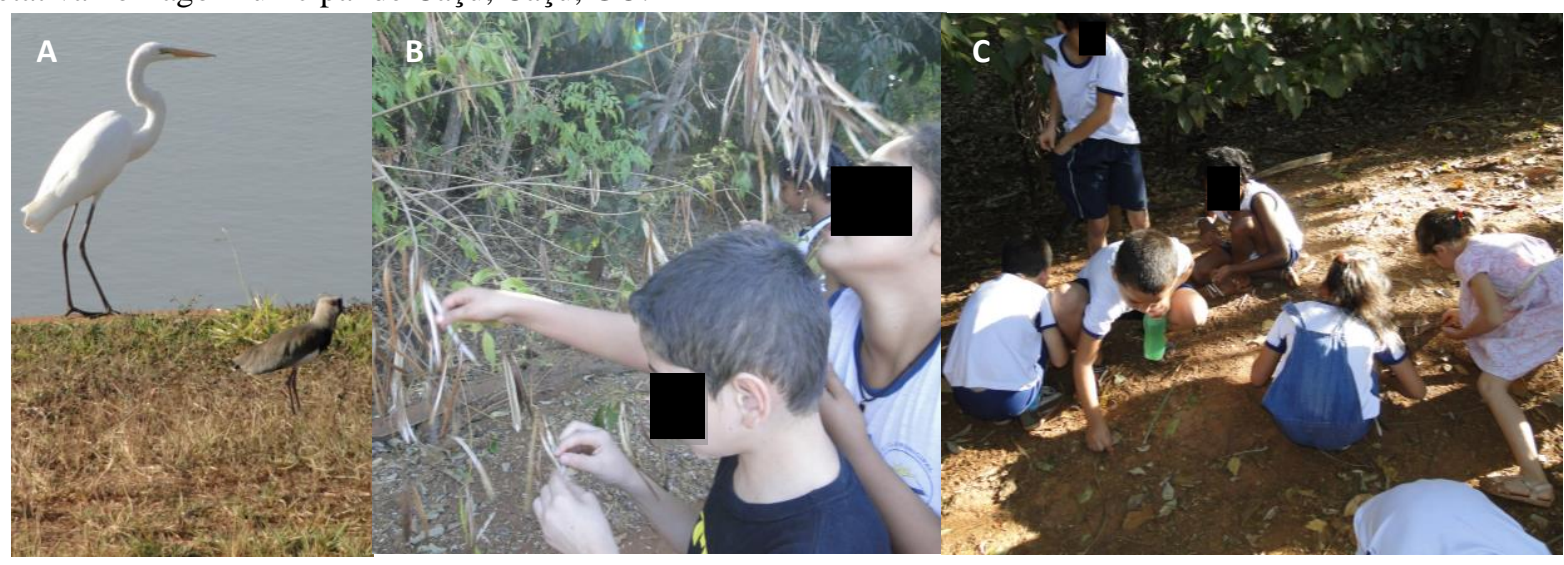

Fonte: Autores.

Ao desenvolverem a atividade proposta "Fiscais da Natureza" os alunos estiveram atentos a situações de degradação ambiental, aguçando um olhar reflexivo para o lixo encontrado ao longo da Trilha Interpretativa. O momento também oportunizou um maior esclarecimento sobre a importância de descartar o lixo em lugares adequados. Como o Lago Municipal de Caçu possui duas lagoas, área reflorestada, parquinho e está localizado em um bairro residencial, ele é muito utilizado para caminhadas e recreação das crianças. O intenso fluxo de pessoas influencia na geração de grande quantidade de lixo no local. Logo, durante a realização da Trilha Interpretativa as crianças recolheram cerca de $1 \mathrm{~kg}$ de lixo, constituído de latas, garrafas PET e plástico. Esse lixo foi conduzido para lixeiras específicas, incentivando o descarte e separação correta do material para aproveitamento dos catadores locais.

O percurso da Trilha Interpretativa pelo público-alvo teve duração de uma hora. É importante ressaltar que as crianças mostraram-se interessadas e curiosas pelo ambiente que as cercava durante todo o percurso. Ao final desta atividade, em uma conversa informal, as crianças foram estimuladas a refletir e a expressar sua opinião acerca dos possíveis usos que essa área verde poderia ter. Foram mencionados pelas crianças que os usos da Trilha Interpretativa podem abranger: passear, contemplar, ensinar, brincar, coletar sementes e ver e aprender sobre os animais e as plantas. Transformar a teoria da sala de aula em prática, usando os recursos ecológicos como o uso de Trilhas Interpretativas, consiste em um método importante em ações no âmbito da EA (Santos et al., 2011; Rocha et al., 2017; Alvarenga et al., 2018; Rocha \& Henrique, 2020). As Trilhas Interpretativas são utilizadas em projetos como meio de interpretação ambiental visando não somente a transmissão de conhecimentos, mas também propiciando atividades que analisam os significados dos eventos observados no ambiente bem como as características do mesmo (Zanin, 2006). Esses espaços podem servir como via de condução a atrativos ou ambientes naturais, para contemplação do ambiente natural, prática de ecoturismo, recreação e esportes radicais (Gualtieri-Pinto et al., 2008). Além de propiciar o contato com a natureza, o descanso e a fruição são também meios eficazes na interação homem/natureza e podem contribuir na formação da consciência ambiental (Siqueira, 2004).

A sensibilização das crianças participantes da pesquisa pode ser corroborada pelos relatos das professoras mediante situações vivenciadas delas com as crianças no cotidiano escolar após a visita à Trilha Interpretativa. As professoras relataram o que passaram a ouvir sobre observações da natureza vivenciadas no dia a dia pelas crianças: “...tem uma mudinha crescendo no meu quintal...”; “lá em casa, estamos deixando o plástico em sacos separados para o catador recolher...”; “embaixo do ipê está parecendo um tapete rosa...". Resultados similares foram corroborados por Santos et al. (2011) os quais afirmam que com os trabalhos desenvolvidos por meio das trilhas ecológicas interpretativas percebe-se uma maior interação dos alunos com a natureza, motivando-os a usarem sua criatividade e provocando nestes, atitudes capazes de, na prática, desenvolverem uma 
consciência mais voltada à conservação do ambiente.

A sensibilização também pode ser observada nas ilustrações que as crianças produziram acerca do que viram ao realizar o percurso da Trilha Interpretativa (Figura 6). Todas as crianças participantes da visita à Trilha Interpretativa fizeram um desenho ilustrando o que mais lhe chamou a atenção e corrobora com a eficácia desta metodologia através de tentar mostrar a percepção ambiental através de desenhos. A maioria do público infanto-juvenil gosta de desenhar, logo, a adequação e vantagem dessa ferramenta em pesquisas com jovens e crianças se dá pela fácil aceitação, assim como pelo fato de ser um recurso relaxante e de linguagem universal, além de proporcionar uma imagem próxima do que a criança percebeu e apreendeu acerca de um determinado tema (Profice et al., 2013; Gonzalez \& Rocha, 2019; Morais et al., 2021a). Percebe-se, com os resultados aqui apresentados que a Alfabetização Ambiental foi desencadeada, haja vista que, conceitos intrínsecos à conservação ambiental estão sendo vivenciados, construídos e perpetuados no intelecto das crianças participantes da pesquisa. Isso comprova a importância de despertar nas crianças essa curiosidade sobre a natureza e aguçar o seu olhar tanto para os fenômenos ecológicos, quanto para os impactos ambientais resultantes das ações antrópicas, utilizando como ferramenta socioeducativa a Trilha Interpretativa. Porém, as ações, dependem de um esforço contínuo de pais, professores e da comunidade em geral para que este processo continue e seja ampliado.

Figura 6. Ilustrações feitas pelas crianças participantes da pesquisa após a visita à Trilha Interpretativa.

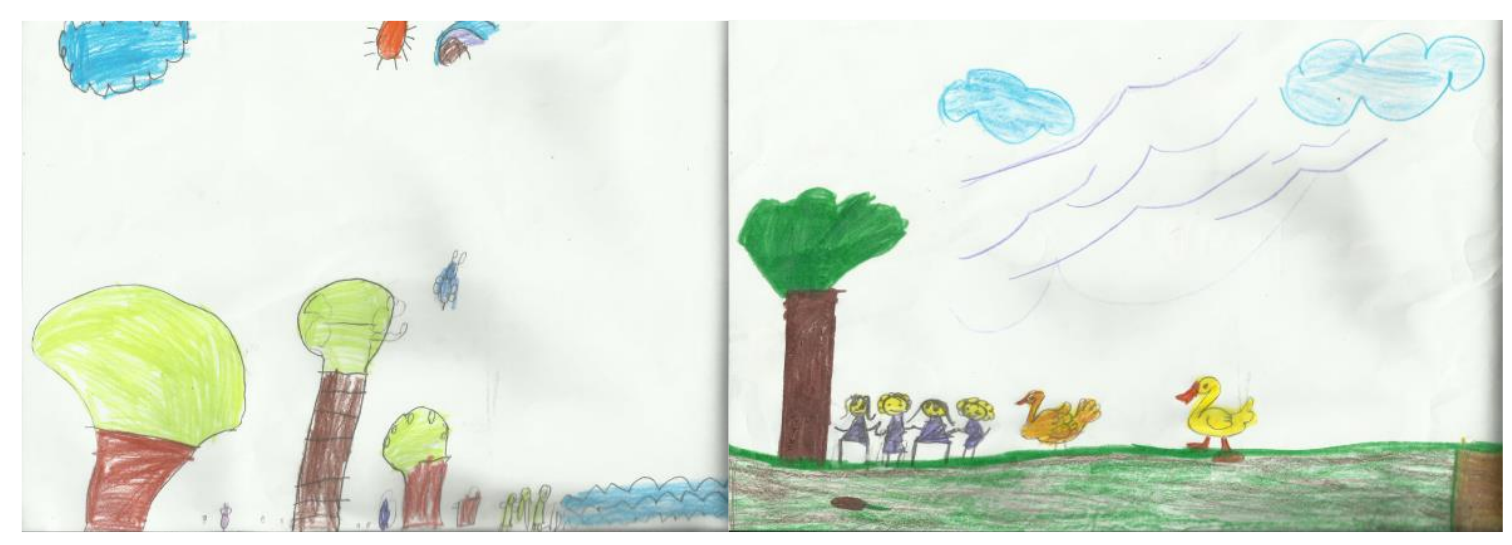

Fonte: Autores.

A Trilha Interpretativa é uma das ferramentas de educação ambiental que ajuda a promover a percepção das pessoas, de modo que possam despertar o interesse pela preservação de um espaço ao qual elas têm acesso e contato com outros seres vivos. Há o reconhecimento crescente de que o envolvimento da população local é o elemento principal que está faltando nas estratégias de manejo e conservação (Primack \& Rodrigues, 2001; Silva et al., 2012; Costa et al., 2014; Rocha et al., 2017). A Trilha Interpretativa busca também a constituição de eficiente desenvolvimento da dimensão educativa inclusiva, haja vista que, integrando o público-alvo, haviam crianças com déficit intelectual e baixa visão. As expressões relatadas por essas crianças em especial, mostraram que a vivência da Trilha Interpretativa vai além de um simples passeio e constitui uma atividade de cunho sensorial, no qual aspectos ambientais que muitas vezes não poderiam ser compreendidos, puderam ser apreendidos na forma mais literal da palavra.

Também houve procura de professores de outras turmas almejando desenvolver atividades de cunho sensorial em ambientes verdes em outros locais. Isso mostra que há necessidade de incentivar essas práticas entre os profissionais da escola. Nas etapas da Educação Básica subsequentes, não é dada sequência à EA. Com isso, conceitos de cuidado com o ambiente vão sendo esquecidos pela falta de vivência. E nesse aproveitamento de áreas verdes urbanas, as experiências sensoriais que a natureza pode trazer, além da saída da rotina escolar, inferem na memória dessas crianças a criação de situações de incentivo à 
conservação da natureza ao longo da vida.

\section{Considerações Finais}

A implementação da Trilha Interpretativa com o uso de situações lúdicas, sensoriais e culturais para crianças do Ensino Fundamental no Lago Municipal de Caçu, proporcionou uma mudança de atitude nas crianças participantes, despertando a conscientização em relação à conservação dos recursos naturais, coleta seletiva do lixo e uma ampliação do olhar para a natureza vivenciada no seu cotidiano.

A Trilha Interpretativa é uma oportunidade de contribuir para o processo de Alfabetização Ambiental nas crianças de forma natural, recreativa, prazerosa e intrínseca às relações de cunho cognitivo, perceptual e afetivo com o meio ambiente, com transformações atitudinais e comportamentais. Essa ferramenta estimula a capacidade investigadora, levando as crianças a repensarem seu modo de ver e sentir o mundo à sua volta, a partir da interpretação e da percepção da realidade ambiental. Dessa forma, a Trilha Interpretativa se firma como ferramenta facilitadora do aprendizado ambiental e consiste em uma estratégia para a proteção dos recursos naturais.

Entretanto, é fulcral que esta proposta seja perpetuada, diversificada e ampliada, para que as informações, conceitos, interpretação e sensibilização ambiental permaneçam presentes e sejam disseminados na comunidade local e não sejam esquecidos com o passar do tempo. Assim, esperamos que a nossa pesquisa possa subsidiar estudos futuros, com possibilidades de roteiros de práticas ambientais para monitoria de visitas escolares, direcionadas a estudantes da educação básica, associando aprendizagem, conhecimento de espécies da fauna, flora e funga presentes na trilha e a conservação ambiental.

\section{Agradecimentos}

Agradecemos às crianças que participaram da pesquisa e à comunidade escolar da Escola Municipal Olívio Girotto.

\section{Referências}

Alvarenga, C. A.; Oliveira, C. M. V. C. de; Ferreira, A. L. R.; Silva, P. B. S.; Gregório, F. S. F.; Cesar, G. C. L. \& Ribeiro, L. A. (2018). Trilha interpretativa para promoção da educação ambiental na Funcesi, Itabira Minas Gerais. Research, Society and Development, 7 (1), e1271186.

Andrade, W. J. \& Rocha, R. F. (2008). Manejo de trilhas: um manual para gestores. São Paulo: Instituto Florestal.

Barros, C. B. R. de; Soares, W. A. \& Holanda, M. A. C. R. de. (2021). Influência do substrato dos telhados verdes na redução do escoamento superficial quando submetido às condições climáticas da Região Metropolitana do Recife. Research, Society and Development, 10 (5), p. e57710515401.

Brasil. (1999). Lei n ${ }^{\circ}$ 9.795, de 27 de abril de 1999. Dispõe sobre a educação ambiental, institui a Política Nacional de Educação Ambiental e dá outras providências.

Campos, M. M. \& Rosemberg, F. Critérios para um atendimento em creches que respeite os direitos fundamentais das crianças. 6. ed. Brasília: MEC, SEB, 2009. 44 p.

Capra, F. (2002). A teia da vida. São Paulo: Cultrix.

Catanhede, A. M.; Silva, R. L.; Silva, H. A. \& Borges, T. C. (2016). Análise da percepção ambiental, por meio de desenhos, de alunos do ensino fundamental numa escola da zona rural, Chapadinha-MA. Revista da SBEnBio, 9, 6561-6570.

CNS (Conselho Nacional de Saúde). (2012). Resolução no 466, de 12 de dezembro de 2012. 〈https://conselho.saude.gov.br/resolucoes/2012/Reso466.pdf>. 13.Jul.2018.

CNS (Conselho Nacional de Saúde). (2016). Resolução no 510, de 07 de abril de 2016. <http://conselho.saude.gov.br/resolucoes/2016/Reso510.pdf>. 14.Mai.2018

CONAMA (Conselho Nacional de Meio Ambiente). (2006). Resolução CONAMA No 369/2006. Dispõe sobre os casos excepcionais, de utilidade pública, interesse social ou baixo impacto ambiental, que possibilitam a intervenção ou supressão de vegetação em Área de Preservação Permanente - APP.

Costa, E.; Costa, I.; Oliveira, K. S. \& Melo, A. V. (2014). Trilhas interpretativas na área verde da escola como estratégia de ensino para aprendizagem de conceitos ecológicos. Revista da SBEnBio, 7 (2), 1820-1831.

Dick, A. P.; Silva, J. C. R. da; Henckes, S. B. R.; Marchi, M. I. \& Strohschoen, A. A. G. (2020). Saídas de campo: uma possibilidade para o ensino de matemática. Research, Society and Development, 9 (1), e41911563. 
Gardner, H. (1995). Inteligências Múltiplas: a teoria na prática. 1. ed. Porto Alegre: Artes Médicas, 257 p.

Gonzalez, A. H. \& Rocha, M. B. (2019). Análise da percepção ambiental de estudantes sobre a Baía de Guanabara através de desenhos. Research, Society and Development, 8 (9), e04891239.

Google Earth. (2021). website. http://earth.google.com/.

Gualtieri-Pinto, L.; Oliveira, F.; Andrade, M.; Pedrosa, H.; De Santana, W. \& Figueiredo, M. (2008). Atividade erosiva em trilhas de Unidades de Conservação: Estudo de caso no Parque Nacional da Serra do Cipó, Minas Gerais, Brasil. Revista Eletrônica E-scientia, 1 (1), $34-44$.

Ibiapino, T. R. \& Nääs, I. de A. (2020). O efeito de resfriamento causado pela arborização como uma solução para o aquecimento urbano: um estudo de caso em Teresina, estado do Piauí, Brasil. Research, Society and Development, 9 (11), e2969119870.

Matos, R. T. de; Oliveira, M. de \& Vásquez, A. G. (2021). Jogos, Brincadeiras e Educação Infantil: notas acerca da construção de gênero. Research, Society and Development, 10 (2), e13610212489.

Ministério da Educação. (2006). Secretaria de Educação Básica. Parâmetros básicos de infraestrutura para instituições de educação infantil. Brasília: MEC, SEB, 45 p.

MMA (Ministério do Meio Ambiente). 2017. <http://www.mma.gov.br/cidades-sustentaveis/areas-verdes-urbanas/parques-e\%C3\%A1reas-verdes>

Morais, I. L. de; Aguiar, D. S.; Rodrigues, S. M. \& Arruda, R. (2021a). O uso de plantas carnívoras como ferramenta para o ensino de botânica e para a educação ambiental. Research, Society and Development, 10 (14), e338101422153.

Morais, I. L. de.; Rizzo, C. D.; Brandelero, S. M. \& Hannibal, W. (2021b). Eficácia de placas educativas no descarte de resíduos sólidos urbanos e à não alimentação do sagui-de-trufo-preto (Callithrix penicillata). Research, Society and Development, 10 (13), e300101321463.

Neres, D. L.; Silva, L. R. C. da \& Pereira, M. A. B. (2021). Influência da vegetação no conforto térmico urbano em município do Sul do Tocantins. Research, Society and Development, 10 (6), e47810615999.

Nunes, R. O.; Reis, P. G. R. dos \& Oliveira, I. C. (2021). Questões ambientais e a importância da educação em ciências para o empoderamento de indígenas da Amazônia. Research, Society and Development, 10 (1), e8110111457.

Peixoto, S. C.; Nora, L. D. D.; Conceição Meireles Ortiz, A.; Topolski, D. K.; Orselli, M. I. V. \& Nunes, J. F. (2021). A dimensão interdisciplinar na construção da Educação Ambiental: Uma proposta de sequência didática. Research, Society and Development, 10 (5), e15710514808.

Pereira, A. S.; Shitsuka, D. M.; Parreira, F. J. \& Shitsuka, R. (2018). Metodologia da pesquisa científica. Ed. UAB/NTE/UFSM. URL <https://repositorio.ufsm.br/bitstream/handle/1/15824/Lic_Computacao_Metodologia-Pesquisa-Cientifica.pdf?sequence=1 >.

Primack, R. B. \& Rodrigues, E. Biologia da Conservação. Londrina: 2001.

Profice, C. C.; Pinheiro, J. Q.; Fandi, A. C. \& Gomes, A. R. J. (2013). Janelas para a percepção infantil de ambientes naturais. Psicologia em Estudo, 18 (3), $529-539$.

Rocha, W. S.; Pasqualetto, A.; Nunes, E. D. \& Guimarães, C. M. (2021). Análise da eficiência hidrológica dos parques urbanos localizados na bacia do córrego Botafogo, Goiânia, GO. Research, Society and Development, 10 (15), e15101519980.

Rocha, M. B. \& Henrique, R. L. S. (2020). Contribuição das Trilhas Interpretativas no Ensino Superior: O Caso da Trilha do Estudante, Rio de Janeiro, Brasil. Sisyphus - Journal of Education, 8, (2), 49-69.

Rocha, M. B.; Pin, J. R. O.; Goés, Y. C. B. \& Rodrigues, L. A. (2017). Contribuições de uma trilha ecológica para as percepções de meio ambiente dos estudantes. Debates em Educação Científica e Tecnológica, 7 (2), 19-43.

Santos, M. C. dos; Flores, M. D. \& Zanin, E. M. (2011). Trilhas interpretativas como instrumento de interpretação, sensibilização e Educação Ambiental na APAE de Erechim/RS. Vivências, 7 (13), 189-197.

Secretariat of the Convention on Biological Diversity. (2012). Cities and Biodiversity Outlook. Montreal. 64 p.

Silva, M. M.; Neto, T. A.; Azevedo, L. F.; Scarton, L. P. \& Hillig, C. (2012). Trilha Ecológica como prática de Educação Ambiental. Revista Eletrônica em Gestão, Educação e Tecnologia Ambiental, 5 (5), 705-719.

Silvestrim, E. G.; Vieira, M. R. S.; Silvestrim, F. G.; Lima Filho, A. A. de \& Lopes, A. B. (2021). Uma visão sobre a degradação ambiental causada pelas ocupações irregulares em áreas verdes na cidade de Manaus-AM. Research, Society and Development, 10 (16), e290101623764.

Siqueira, L. F. (2004). Trilhas interpretativas: Uma vertente responsável do (eco) turismo. Caderno Virtual de turismo, 14.

Telles, C. A. \& Silva, G. L. F. (2012). Relação criança e meio ambiente: Avaliação da percepção ambiental através da análise do desenho infantil. Revista Tecnoeng., 6 (3), 23-40.

Verde, M. R. V.; Santana, L. S. G. de; Almeida, P. N. L. de; Reis, R. B.; Mello, M. M. C. \& Cavalcante, M. M. (2020). Expansão urbana e redução de áreas verdes em Salvador/BA: o caso do Parque São Bartolomeu. Research, Society and Development, 9 (10), e1199106913.

Vigigal, M. C. \& Resende, I. L. M. Florística e fenologia do componente arbóreo do Jardim Botânico da UEG, UnU-Quirinópolis. In: XII Simpósio de Iniciação Científica, 2011, Quirinópolis. Anais... Quirinópolis: UEG, 2011.

Yin, R.K. (2009). Case study research, design and methods (applied social research methods). Thousand Oaks. California: Sage Publications.

Zanin, E. M. (2006). Projeto trilhas interpretativas: a extensão, o ensino e a pesquisa integrados à conservação ambiental e à educação. Vivências: Revista Eletrônica de Extensão da URI, 1 (1), 26-35. 